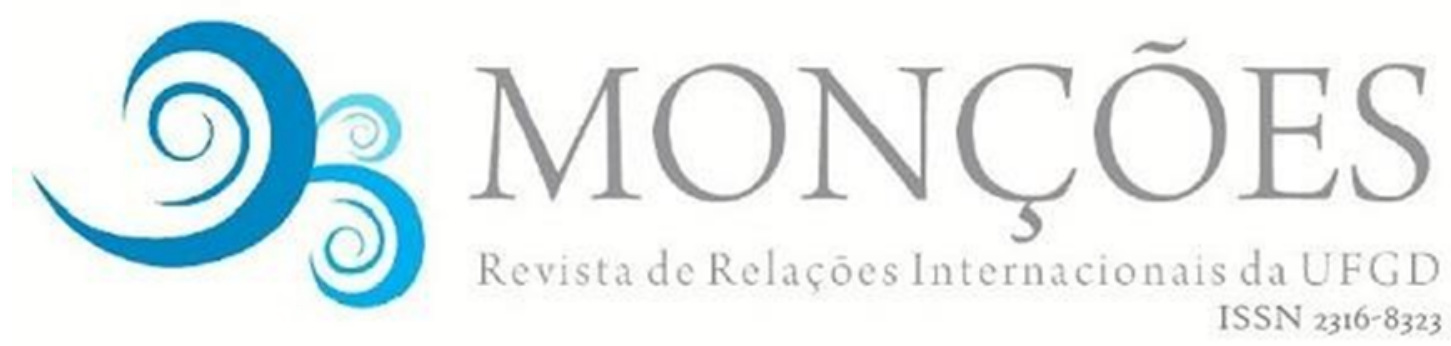

\title{
EMPRESAS MILITARES E DE SEGURANÇA PRIVADA NOS MARES: NOVOS POSICIONAMENTOS SOBRE OS SERVIÇOS DE PROTEÇÃO ARMADA CONTRA A PIRATARIA ${ }^{1}$
}

\author{
GABRIEL PATRIARCA \\ Universidade Estadual de Londrina (UEL), Programa de Pós-Graduação em \\ Sociologia. Londrina, Paraná, Brasil. \\ ORCID: https://orcid.org/0000-0002-9344-7041 \\ gabriel-patriarca@hotmail.com

\begin{abstract}
CLEBER DA SILVA LOPES
Universidade Estadual de Londrina (UEL), Departamento de Ciências Sociais. Londrina, Paraná, Brasil. ORCID: https://orcid.org/0000-0002-2197-159X clopes@uel.br
\end{abstract}

Resumo: Refletindo uma responsabilidade estatal pela segurança marítima estabelecida há pelo menos um século e meio, posicionamentos contrários à proteção armada de embarcações civis foram sustentados por diversos stakeholders do transporte marítimo. Contudo, nas duas últimas décadas, o ressurgimento da pirataria e do roubo armado contra navios promoveu a prestação de serviços de proteção armada por empresas militares e de segurança privada (EMSPs), primeiro no Sudeste Asiático e depois no Chifre da África. No segundo caso, o fenômeno provocou mudanças nos posicionamentos anteriormente contrários à prática, notados pela literatura especializada de maneira fragmentada e genérica. Este artigo revisa essa literatura com o objetivo de explorar o modo como novos posicionamentos foram estabelecidos diante do maior protagonismo assumido pelas EMSPs, analisando as condições e a direção dessas mudanças. $O$ trabalho identifica um ponto de inflexão nos posicionamentos de algumas das principais associações da indústria de transporte marítimo, do maior mercado de seguros marítimos, da Organização Marítima Internacional e dos Estados de bandeira e costeiros.

Palavras-chave: empresas militares e de segurança privada; segurança marítima; pirataria marítima.

\section{PRIVATE MILITARY AND SECURITY COMPANIES AT SEA: NEW POSITIONINGS ON ARMED PROTECTION SERVICES AGAINST MARITIME PIRACY}

Abstract: Reflecting a state responsibility for maritime security established at least a century and a half ago, contrary positionings to the armed protection of civilian vessels were supported by several stakeholders of maritime transport. However, in the past two decades, the resurgence of piracy and armed robbery against ships has promoted the provision of armed protection services by private military and security companies (PMSCs), first in Southeast Asia and then at the Horn of Africa. In the second case, the phenomenon has led to positioning changes formerly contrary to such practice, observed by the specialized literature in a fragmented and generic way. This article reviews this literature in order to explore the way in

\footnotetext{
${ }^{1}$ Versões preliminares deste artigo foram apresentadas no $9^{\circ}$ Congresso Latino-americano de Ciência Política (2017) e no I Encontro de Pesquisa sobre Conflitos Internacionais (2018).
} 
which new positionings were established in the face of greater role assumed by PMSCs, analyzing the conditions and the direction of these changes. The article identifies a turning point in the positioning from some of the main associations of the shipping industry, from the largest maritime insurance market, from the International Maritime Organization and Flag and Coastal States.

Keywords: private military and security companies; maritime security; maritime piracy.

\section{EMPRESAS MILITARES Y DE SEGURIDAD PRIVADA EN LOS MARES: NUEVAS POSICIONES SOBRE LOS SERVICIOS DE PROTECCIÓN ARMADA CONTRA LA PIRATERÍA MARÍTIMA}

Resumen: Reflejando una responsabilidad estatal por la seguridad marítima establecida hace por lo menos un siglo y medio, posiciones contrarias a la protección armada de embarcaciones civiles fueron sustentadas por varios stakeholders del transporte marítimo. Sin embargo, en las últimas dos décadas, el resurgimiento de la piratería y el robo armado contra navíos promovió la prestación de servicios de protección armada por empresas militares y de seguridad privada (EMSPs), primero en el Sudeste Asiático y después en el Cuerno de África. En el segundo caso, el fenómeno provocó cambios de posiciones anteriormente contrarias a la práctica, señaladas en la literatura especializada de manera fragmentada y genérica. Este artículo revisa esta literatura con el objetivo de explorar el modo cómo se establecieron nuevas posiciones ante el mayor protagonismo asumido por las EMSPs, analizando las condiciones y la dirección de estos cambios. El trabajo identifica un punto de inflexión en las posiciones de algunas de las principales asociaciones de la industria del transporte marítimo, del mayor mercado de seguros marítimos, de la Organización Marítima Internacional y de los Estados de bandera y costeros.

Palabras clave: empresas militares y de seguridad privada; seguridad marítima; piratería marítima.

\section{INTRODUÇÃO}

A maior parte do domínio marítimo é formada por altos-mares localizados fora da jurisdição de qualquer Estado, uma área anárquica onde navios mercantes movimentam a economia mundial protegidos pela soberania do Estado de sua bandeira de registro (CHALK, 2008; DE NEVERS, 2015a). Há pelo menos um século e meio, tem sido predominante o posicionamento de que a responsabilidade por garantir a segurança marítima e combater as ameaças que afetam esse domínio é inteiramente dos Estados. Navios mercantes responsáveis pelo transporte e pelo comércio no domínio marítimo, assim como outras embarcações civis, não deveriam armar suas tripulações como medida de proteção (FLORQUIN, 2012). Contudo, nas duas últimas décadas, o ressurgimento da pirataria marítima e do roubo armado contra navios pôs em xeque esse posicionamento até então sustentado por diversos stakeholders do transporte marítimo (SPEARIN, 2010a; KRASKA, 2013). Afetando dois corredores estratégicos do transporte internacional, o Estreito de Malaca, no 
Sudeste Asiático, e o Golfo de Áden, no Chifre da África, os ataques abriram um nicho para a prestação de serviços antipirataria por empresas militares e de segurança privada (EMSPs), incluindo a proteção armada por meio de equipes a bordo.

Com a crescente contratação desses serviços pelos armadores, ${ }^{2}$ outros stakeholders passaram a assumir um posicionamento menos intransigente em relação às responsabilidades estatais na segurança marítima, particularmente no caso do Chifre da África. Esse ponto de inflexão foi pontuado pela literatura especializada, mas tratado de maneira fragmentada e genérica. Pouca atenção foi dada ao modo como o consenso internacional contrário à proteção armada de embarcações civis e baseado na ideia do monopólio estatal da provisão da segurança nos mares foi alterado com as EMSPs (AARSTAD, 2017a; LISS, 2017). Este artigo busca contribuir para uma melhor compreensão dessas mudanças a partir de uma revisão da literatura especializada ${ }^{3}$. Analisando os posicionamentos sobre os serviços de proteção armada prestados por EMSPs no Estreito de Malaca e no Golfo de Áden, nossos objetivos são entender as condições que produziram as mudanças nos posicionamentos estabelecidos sobre segurança marítima e a direção que essas mudanças tomaram em relação ao consenso até então contrário à proteção armada.

$\mathrm{O}$ artigo está organizado em quatro seções e conclusão. A primeira discute o crescimento da pirataria marítima e do roubo armado contra navios no Sudeste Asiático e no Chifre da África. A segunda pontua as respostas estatais e intergovernamentais nos dois casos narrados na seção anterior. A terceira explora o surgimento e a expansão da prestação de serviços de proteção armada por EMSPs. A quarta analisa as mudanças nos posicionamentos que há pelo menos um século $\mathrm{e}$ meio eram contrários à proteção armada de embarcações civis e confiavam a responsabilidade pela segurança marítima exclusivamente aos Estados. A conclusão sumariza os posicionamentos revelados pela análise e sugere uma hipótese explicativa acerca das condições que levam ao aparecimento e ao reconhecimento

\footnotetext{
${ }^{2}$ Armador é o nome dado à pessoa física ou jurídica que equipa e explora comercialmente os navios.

${ }^{3}$ Foram realizadas buscas de artigos publicados em periódicos revisados por pares no Portal de Periódicos da Capes e, posteriormente, por meio das referências bibliográficas dos trabalhos coletados. Os termos de busca utilizados foram "Private Security Companies" AND "Piracy"; "Private Military Companies" AND "Piracy"; "Private Military and Security Companies" AND "Piracy"; e "Private Maritime Security Companies". Todo o processo de identificação e coleta foi realizado durante o primeiro semestre de 2017. Ao todo, foram analisados 99 trabalhos.
} 
dos serviços de proteção armada de navios por EMSPs, tradicionalmente rejeitados pelos stakeholders do domínio marítimo.

\section{A PIRATARIA E O ROUBO ARMADO CONTRA NAVIOS NO INÍCIO DO SÉCULO} XXI

Remonta ao romano Cícero (106 a.C. - 63 a.C.) o título concedido aos piratas como hostis humani generis, "inimigos de toda a humanidade" por ameaçarem a liberdade da navegação, da qual todos potencialmente podem se beneficiar, e por cometerem crimes em alto-mar, um bem de todos que está além da jurisdição de qualquer Estado (SPEARIN, 2010b). Atualmente, a definição de pirataria marítima legalmente vigente é estabelecida pelo Artigo 101 da UNCLOS, a Convenção das Nações Unidas sobre o Direito do Mar (ONU, 1982), que inclui qualquer ato ilegal de violência, detenção ou depredação, cometido para fins privados pela tripulação ou pelos passageiros de uma embarcação privada, em alto-mar, contra outra embarcação ou pessoas e bens a bordo. A definição contempla os atos realizados depois de 12 milhas náuticas da linha de base do Estado costeiro, extensão que marca o início das águas internacionais. Ainda que sejam idênticos aos da definição, os atos cometidos em mares territoriais estão submetidos à jurisdição do Estado costeiro e são definidos por sua legislação específica (LORCA, 2017). Apesar de não ser uma definição legal, a IMO e outras organizações internacionais costumam denominar esses atos em mares territoriais como roubo armado contra navios (BECKMAN; PAGE, 2014). Outras entidades adotam definições diferentes da UNCLOS, ou adotam simultaneamente as definições de pirataria e roubo armado, com o objetivo de contemplar todos os atos cometidos dentro e fora de jurisdição estatal. Esse é o caso do International Maritime Bureau (IMB), divisão especializada da Câmara Internacional de Comércio que mantém uma das principais fontes de dados sobre o problema no mundo contemporâneo, demonstrando que "a pirataria, além de viva e bem, está recrudescendo" (SEKULICH, 2009, p. 23).

As águas do Sudeste Asiático foram as primeiras a chamar a atenção do IMB. Ainda que os ataques na região ocorressem há décadas, principalmente nos mares territoriais da Indonésia, a pirataria e o roubo armado contra navios foram fonte de preocupação internacional quando atingiram o Estreito de Malaca, uma via estratégica para o transporte marítimo internacional, no ano 2000 (LISS, 2007; 2013b). Em 1999, 
apenas dois ataques no estreito foram registrados pelo IMB, número que saltou para 75 no ano 2000 (IMB, 2005). Além desse aumento drástico, alguns ataques no Estreito de Malaca também se diferenciaram dos roubos de menor gravidade predominantes na região, com casos envolvendo sequestros de tripulações em troca do pagamento de resgate (LISS, 2013b; 2017). Contudo, após o aumento no ano 2000, o estreito viu números relativamente altos de pirataria e roubos contra navios apenas em 2004, quando 38 ataques foram registrados, caindo consecutivamente para 12, 11 e 7 ataques nos três anos seguintes. Em todo o Sudeste Asiático, a tendência ao longo da década foi de diminuição no número de ataques registrados (IMB, 2005; 2009; 2013).

Nesse mesmo período, a Somália passava a chamar atenção internacional. Além do crescente número de casos registrados em seus mares territoriais, ataques realizados em outras águas do Chifre da África foram atribuídos aos piratas somalis, incluindo o Golfo de Áden, outra via estratégica para o transporte marítimo internacional (IMB, 2010). Os ataques aumentaram drasticamente a partir de 2008, quando 111 casos foram atribuídos aos piratas somalis. Nos três anos seguintes, esses números foram ainda maiores - 218 casos registrados em 2009, 219 em 2010 e 237 em 2011 (IMB, 2009; 2013). Uma das principais motivações da pirataria somali é a obtenção de grandes quantias de dinheiro mediante o sequestro de navios, cargas e tripulações em troca do pagamento do resgate, em negociações que podem levar meses ou anos (LISS, 2013b; 2017). O Banco Mundial (2013) estima que, de abril de 2005 a dezembro de 2012, foram pagos entre 339 e 413 milhões de dólares para piratas somalis. Nos três anos com mais casos registrados pelo IMB, estima-se que foram pagos entre 57 e 84 milhões de dólares no ano de 2009; entre 70 e 90 milhões no ano de 2010; e entre 151 e 156 milhões no ano de 2011. Outras estimativas mostram valores ainda maiores, com a mesma tendência de crescimento (FLORQUIN, 2012).

Diferentes fatores foram elencados para explicar esse ressurgimento da pirataria e o modo como ela se manifestou nos dois casos. No Sudeste Asiático, os ataques aumentaram principalmente após a crise financeira asiática de 1997, cujo efeito econômico e a relativa instabilidade política resultante foram considerados como fatores decisivos para os crimes marítimos - além de que os casos mais graves, como aqueles que envolveram sequestros, podem ter impulsionado a notificação dos 
ataques na região (RAYMOND, 2009). Às condições socioeconômicas, Frécon (2008) adiciona o fraco controle estatal exercido sobre partes específicas da região, como arquipélagos explorados pelos piratas. Por sua vez, o ressurgimento da pirataria somali remonta ao início da década de 1990, com o colapso do regime de Siad Barre e a posterior fragmentação do Estado somali (KISIANGANI, 2010). O próximo governo somali reconhecido internacionalmente veio apenas em 2004, mas ainda contando com capacidades limitadas e disputadas com outras forças políticas que passaram a controlar grande parte do território (HANSEN, 2008). A fragilidade do governo nacional e a fragmentação do território somali, segundo Onuoha (2009), foram acompanhados pelo fortalecimento de "senhores da guerra" e milícias direta ou indiretamente envolvidas com a pirataria.

Tanto no Sudeste Asiático quanto no Chifre da África, o ressurgimento da pirataria e do roubo contra navios provocou reações estatais que refletiram as diferentes condições dos Estados costeiros, com resultados distintos no que diz respeito ao espaço deixado para a atuação de atores não estatais, até então excluídos desse cenário da segurança marítima. As próximas seções discutem essas questões.

\section{AS RESPOSTAS ESTATAIS À PIRATARIA: A REAFIRMAÇÃO DO CONSENSO}

O modo como a segurança nos mares vem sendo concebida e realizada reflete uma divisão de responsabilidades estabelecida desde a metade do século XIX, quando os Estados passaram a assumir o combate às ameaças que afetam esse domínio, como a pirataria. Marinhas, guardas costeiras e outras forças estatais seriam as únicas capazes de usar a força legitimamente, enquanto as embarcações civis e os atores privados em geral seriam responsáveis única e exclusivamente pelo transporte e pelo comércio (FLORQUIN, 2012; AARSTAD, 2017a). Essa responsabilidade estatal foi afirmada em convenções e tratados sobre o domínio marítimo, incluindo aquelas que lidam com a pirataria. Uma das consequências da consideração dos piratas como inimigos da humanidade é a jurisdição universal. Piratas podem ser perseguidos, capturados e processados de acordo com as leis de um Estado, mesmo que o ataque não tenha ocorrido no interior de seu território (BURGESS, 2006). Hoje, a jurisdição universal é afirmada no Artigo 105 da UNCLOS. Fora da jurisdição de qualquer Estado, cada Estado tem o direito de capturar um navio pirata ou por eles tomado, prender os piratas, apreender os bens a bordo e decidir 
sobre as penas. O Artigo 107 especifica que esse direito é atribuído a aeronaves militares, navios de guerra ou outras embarcações identificadas como unidades governamentais autorizadas (ONU, 1982).

O ressurgimento da pirataria marítima provocou diversas respostas estatais que reafirmaram esse consenso. Desde o começo dos anos 1990, em maior ou menor medida, muitos países do Sudeste Asiático fortaleceram suas forças navais e estabeleceram novas agências especializadas para garantir a segurança de suas águas territoriais (LISS, 2013a). Com o aumento dos casos de pirataria e roubo armado no Estreito de Malaca nos anos 2000, a pressão internacional recaiu sobre Malásia, Singapura e Indonésia, três Estados costeiros cujas águas compõem grande parte do Estreito. Inicialmente, os esforços nacionais realizados pelos Estados costeiros enfrentavam recursos limitados, principalmente na Malásia e na Indonésia esta última, particularmente debilitada pela crise financeira asiática de 1997. A coordenação regional também enfrentava discordâncias sobre a prioridade do problema diante de outras questões internas, muitas delas oriundas da crise, além de ênfases na defesa da soberania das águas territoriais, principalmente por parte de Malásia e Indonésia, em um cenário com antigas reivindicações de soberania sobre ilhas e outras áreas marítimas (RAYMOND, 2009; LISS, 2013a; 2013b). Exemplificando a sensibilidade das questões relacionadas à soberania, o apoio de patrulhas estatais estrangeiras no combate à pirataria foi rejeitado pelos Estados costeiros do Estreito de Malaca (LOBO-GUERRERO, 2012).

Além de respostas nacionais mais consistentes, passos mais firmes em direção à coordenação regional foram dados a partir de julho de 2004, quando os três Estados costeiros estabeleceram a Trilateral Coordinated Patrol, ou MALSINDO, um esquema de patrulhas coordenadas envolvendo as três marinhas em suas respectivas águas territoriais. Posteriormente, em setembro de 2005, Malásia, Singapura e Indonésia, além de Tailândia, estabeleceram o Eyes in the Sky, um plano de patrulhas aéreas conjuntas sobre o Estreito de Malaca. O plano dava um passo além da MALSINDO, que limitava a atuação das forças navais em suas respectivas águas territoriais, ao permitir que as aeronaves sobrevoassem até três milhas náuticas sobre as águas territoriais dos países participantes. Em abril de 2006, a MALSINDO e a Eyes in the Sky foram unidas na Malacca Strait Patrols (RAYMOND, 2009). 
A pirataria no Golfo de Áden recebeu respostas distintas, dada a fragilidade do Estado somali. De fato, houve uma exceção à regra de que os Estados costeiros possuem jurisdição exclusiva em seus mares territoriais. Em 2008, a Resolução 1816 do Conselho de Segurança da ONU autorizou os Estados em cooperação com o governo somali reconhecido na época, o Governo Federal Transicional (TFG), a realizar perseguições e apreensões por pirataria no mar territorial da Somália - uma medida temporária que passou a ser regularmente renovada (BECKMAN; PAGE, 2014; TUERK, 2015). Essa resolução estabeleceu as bases para operações multilaterais antipirataria. Em dezembro de 2008, a União Europeia estabeleceu sua força naval, a European Union Naval Force (EUNAVFOR), e sua primeira operação militar marítima, a Operação Atalanta. Em agosto de 2009, a OTAN estabeleceu a Operação Ocean Shield em substituição às operações temporárias Allied Provider e Allied Protector, realizadas desde outubro de 2008. Sob a liderança dos Estados Unidos, foram criadas as Combined Maritime Forces, cuja principal força-tarefa foi a Combined Task Force 151, estabelecida em janeiro de 2009. Outros países enviaram navios individualmente em patrulhas antipirataria, como China, Índia, Japão, Rússia, Coreia do Sul e Irã (BROWN, 2012; VAN GINKEL; LANDMAN, 2012; GHOSH, 2014; TUERK, 2015).

Contudo, essas operações multilaterais tiveram como efeito uma ampliação da área de risco da pirataria somali, que se espalhou por 8,3 milhões de $\mathrm{km}^{2}$ de oceano (BROWN, 2012). Nesse cenário, a pirataria somali recebeu outra resposta singular. Buscando uma medida de caráter defensivo, diversos países possibilitaram a contratação de equipes policiais ou militares para a proteção armada a bordo dos navios comerciais sob sua bandeira, como Reino Unido, Itália, França, Alemanha, Noruega e Holanda (FARNELLI, 2015). A disponibilização dessas equipes, denominadas Vessel Protection Detachments (VPDs), também fez parte de operações como a EUNAVFOR, possibilitando a contribuição de países incapazes de fornecer navios de guerra (HARLOW, 2012). Porém, custos elevados, pouca flexibilidade e longos processos de aplicação fizeram dos VPDs uma opção pouco utilizada - mesmo em navios de bandeira holandesa, país com uma das principais iniciativas governamentais para disponibilização dessas equipes (PETRIG, 2013; VAN GINKEL; VAN DER PUTTEN; MOLENAAR, 2013; VAN HESPEN, 2014). 
Portanto, as respostas estatais à pirataria e ao roubo armado contra navios no Sudeste Asiático e no Chifre da África refletiram a responsabilidade estatal pela provisão da segurança nos mares. Grosso modo, no Estreito de Malaca, preocupações relacionadas à soberania foram traduzidas em esforços nacionais e regionais pelos três Estados costeiros, enquanto a fragilidade do Estado somali abriu espaço para operações multilaterais no Golfo de Áden, além da disponibilização de equipes estatais a bordo dos navios mercantes - uma primeira mudança na ideia de que embarcações civis não deveriam portar armamentos, mas ainda ligada à responsabilidade estatal pela segurança marítima. De fato, a disponibilização de VPDs foi fonte de preocupação pela difícil conciliação entre as normas da UNCLOS e o transporte de armas de fogo a bordo dos navios, mas a contratação dessas equipes estatais tornou-se uma prática encorajada em contraposição à alternativa que vinha do setor privado (FARNELLI, 2015). Em grande medida, os aspectos que faziam dos VDPs uma opção pouco utilizada aumentavam a atratividade dos serviços de proteção armada oferecidos por EMSPs, que acabaram provocando mudanças não apenas no posicionamento sobre a proteção armada de embarcações civis, mas na própria ideia de que o Estado é o único responsável pela segurança marítima.

\section{AS RESPOSTAS NÃO ESTATAIS À PIRATARIA: EMSPs NOS MARES}

Uma ampla literatura foi consolidada na área das relações internacionais acerca das EMSPs. De acordo com a síntese realizada por Paoliello (2016), os primeiros estudos sobre o tema surgiram nos anos 1990, refletindo a atuação de EMSPs em guerras civis no continente africano, quando foram associadas ao mercenarismo e consideradas como instrumentos de interferência política em países periféricos, seja em prol de grandes potências ou de corporações transnacionais. Essa imagem negativa causada principalmente pela atuação direta nos combates foi minimizada no final dos anos 1990 e início dos anos 2000, quando uma nova geração de estudos passou a refletir a crescente atuação de EMSPs como peacekeepers em missões humanitárias. Posteriormente, os conflitos no Iraque e no Afeganistão levaram a uma terceira geração de estudos, quando Estados Unidos, Reino Unido e outras potências ocidentais lançaram mão de diversos serviços prestados pelas EMSPs. Um debate mais pragmático sobre questões como ética, eficiência, controle e regulação ganhou força na literatura desde então. 
Subjacente a essa passagem de uma perspectiva negativa para outra pragmática sobre as EMSPs, diversas dinâmicas de oferta e demanda foram elencadas como fontes da legitimidade desses atores. De acordo com Avant (2005) e Singer (2008), o fim da Guerra Fria trouxe um período de profunda instabilidade, com conflitos eclodindo no interior de vários países com instituições frágeis, até então dependentes de apoio ou controle externo. O terrorismo e outras novas ameaças também ganharam força, transformando a natureza dos conflitos e desafiando as capacidades militares. Contudo, mesmo grandes potências passaram por desmobilizações massivas em suas forças militares e reduziram as intervenções no estrangeiro, dado o aumento dos custos políticos dessas ações. Limitações semelhantes foram sentidas por organizações regionais e internacionais, inicialmente consideradas como possíveis estabilizadoras desses novos conflitos. Em conjunto, essas condições deixaram vácuos na segurança no período em que mudanças ideacionais prezavam cada vez mais pelos benefícios da privatização. Assim, demandas por parte de corporações e organismos multilaterais presentes nos países em conflito, bem como por parte desses próprios países ou de grandes potências, foram correspondidas pelo enorme contingente de militares treinados, armamentos e tecnologias oriundos das desmobilizações e que agora compunham o setor privado. As EMSPs assumiram uma estrutura corporativa, geralmente integrando conglomerados e holdings, e passaram a competir abertamente no mercado, a realizar recrutamentos públicos de seus quadros e a prestar uma ampla gama de serviços para clientes igualmente variados.

Em grande medida, essa literatura foi desenvolvida com foco nos acontecimentos em terra. Contudo, a pirataria e o roubo contra navios compõem o rol de novas ameaças que ganharam força após o fim da Guerra Fria - entre outros fatores, pelo descontrole de áreas antes ocupadas e pelas disputas territoriais emergentes no Sudeste Asiático (FRÉCON, 2008), ou pela fragilidade institucional e fragmentação política no Chifre da África (HANSEN, 2008; ONUOHA, 2009). Ainda que termos como Private Maritime Security Companies (IMO, 2011) e Private Naval Companies (BERUBE, 2007) tenham sido propostos com o objetivo de distinguir as EMSPs atuantes nos mares, muitas delas prestam serviços em terra e em mar, não limitando sua atuação a um cenário específico. De fato, algumas EMSPs protagonistas da terceira geração de estudos sobre o tema já prestavam serviços 
antipirataria (AVANT, 2005). Como Brown (2012) indica, dinâmicas semelhantes de oferta também influenciaram essas EMSPs no domínio marítimo, uma vez que a principal característica dos diversos serviços antipirataria oferecidos é a origem militar das habilidades e treinamentos que eles envolvem. Esses serviços incluem consultorias, avaliações de risco, treinamento de tripulações, investigação e recuperação de navios e cargas sequestradas, além da proteção armada por meio de equipes a bordo dos navios mercantes, serviço mais proeminente e controverso (LISS, 2013b).

A prestação de serviços de proteção armada por EMSPs surgiu primeiramente diante do aumento da pirataria marítima e do roubo armado contra navios no Sudeste Asiático, embora tenha se limitado ao Estreito de Malaca, onde as características e a frequência dos ataques justificavam os custos da contratação (LISS, 2016). Mas foi a pirataria somali que promoveu um boom na prestação desses serviços, principalmente no Golfo de Áden (KRASKA 2013). De fato, foi esse boom que trouxe as primeiras estimativas sobre a atuação das EMSPs no domínio marítimo, ainda limitadas pela ausência de um registro oficial, mas inexistes no caso do Estreito de Malaca. Segundo Dutton (2013), entre 200 e 300 EMSPs empregavam pelo menos 2.700 profissionais na área de risco de pirataria somali no ano de 2011, em sua maioria empresas britânicas e norte-americanas criadas no mesmo ano. De acordo com as estimativas do programa Oceans Beyond Piracy (OBP), apresentadas no Gráfico 1, aproximadamente $25 \%$ dos mais de 42 mil navios que transitaram pela área de risco no Chifre da África em 2011 contavam com equipes armadas de EMSPs a bordo, ainda que a proporção tenha variado ao longo do tempo e atingido $50 \%$ ao final do ano. Em 2012, estima-se que essas equipes estiveram a bordo de metade dos navios ao longo de todo o ano. Esse aumento se reflete nos custos com a contratação de EMSPs, estimados entre 1,15 e 1,53 bilhões de dólares no ano de 2012, superior aos custos de todas as atividades militares de combate à pirataria somali - incluindo os orçamentos das três maiores operações em curso, VPDs e outros custos operacionais de navios e aeronaves, estimados em 1,09 bilhões (OBP, 2013). 


\section{Gráfico 1 - Navios com equipes de EMSPs a bordo no Chifre da África (\%)}

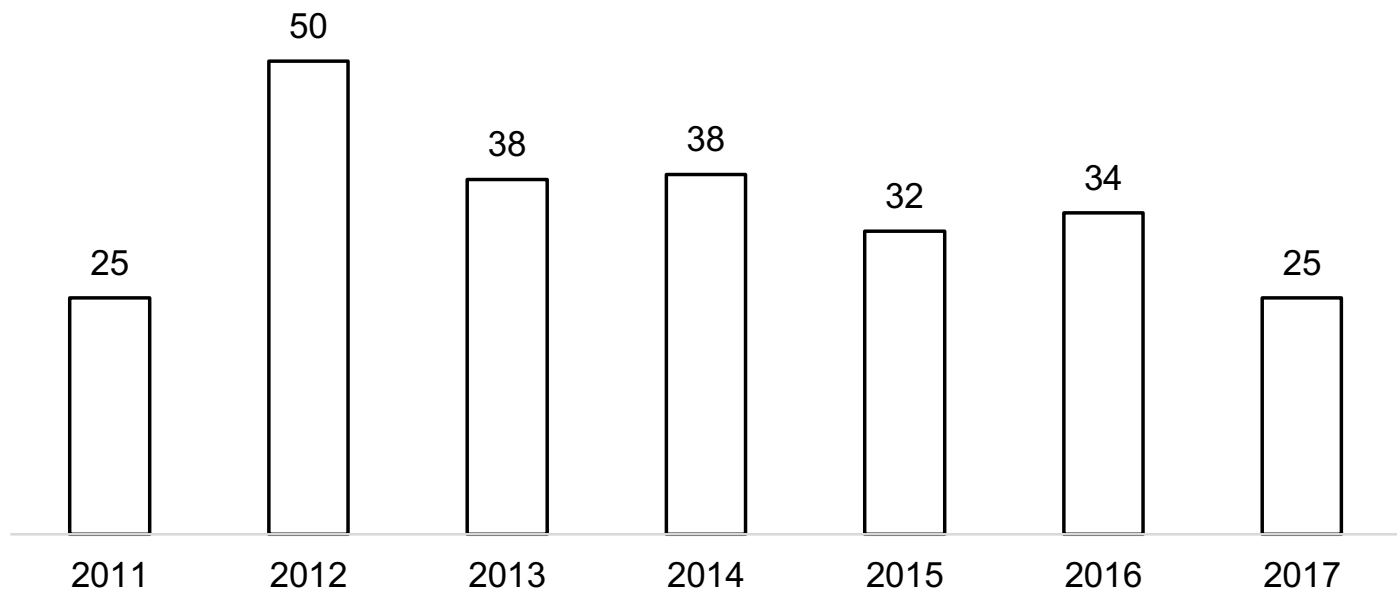

Fonte: elaborado pelos autores a partir de OBP $(2012 ; 2013 ; 2014 ; 2015 ; 2016 ; 2017 ; 2018)$. Alguns relatórios anuais da OBP trazem estimativas únicas e outros trazem estimativas altas e baixas. Os dados do gráfico se referem às estimativas únicas ou à média entre estimativas altas e baixas.

A controvérsia relacionada à proteção armada decorre do desafio que essa prática impõe ao consenso que atribui a responsabilidade pela segurança nos mares exclusivamente às forças estatais, enquanto embarcações civis responsáveis pelo transporte e pelo comércio marítimo não deveriam portar armamentos (FLORQUIN, 2012). Segundo Liss (2017), a proteção armada de embarcações civis não chegou a ser proibida por convenções e tratados, tampouco pela maioria dos Estados. Esse consenso dependeu menos de proibições e mais de processos diversos que promoveram a facilitação do transporte marítimo por meios diplomáticos e diminuíram ameaças como a pirataria. Assim, ainda que essa separação entre responsabilidades públicas e privadas nunca tenha sido absoluta, a construção dessas duas esferas institucionalizou-se como ideal e, em grande medida, também como prática, vigorando até recentemente entre os principais stakeholders do domínio marítimo (SPEARIN, 2010a; KRASKA, 2013; AARSTAD, 2017a). Contudo, o ressurgimento da pirataria e do roubo contra navios representou um ponto de inflexão nesses posicionamentos, particularmente no Chifre da África.

Além dos armadores individuais que passaram a contratar os serviços de proteção armada e das próprias EMSPs que buscaram defender seu espaço na segurança marítima, a revisão da literatura permite distinguir novos posicionamentos adotados por pelo menos cinco categorias de stakeholders. Entre elas estão duas 
indústrias relacionadas aos mares, a do transporte e a dos seguros. A indústria do transporte marítimo engloba as grandes associações internacionais que representam a maior parte da frota mercante mundial, como a International Chamber of Shipping (ICS), o Baltic and International Maritime Council (BIMCO) e o International Group of Protection \& Indemnity Clubs (IGP\&I), enquanto a indústria de seguros marítimos é representada especificamente pela Lloyd's of London, maior mercado global do segmento. Outras categorias envolvem os stakeholders multilaterais, como a IMO, agência especializada da ONU responsável pela segurança da navegação, e os Estados, distinguidos em Estados de bandeira e Estados Costeiros. Enquanto Estados de bandeira, os países regulam as atividades dos navios registrados em seu território; enquanto Estados costeiros, regulam as atividades dos navios que navegam por suas águas territoriais. A próxima seção explora o ponto de inflexão nos posicionamentos desses stakeholders, comparando os casos do Estreito de Malaca e do Golfo de Áden.

\section{A MUDANÇA NO CONSENSO ESTABELECIDO}

A revisão da literatura permite identificar diferentes posicionamentos reprobatórios e tolerantes frente aos serviços de proteção armada prestados por EMSPs no Estreito de Malaca e no Golfo de Áden. Por um lado, os posicionamentos reprobatórios incluíram oposições à prática, interpretada como uma grave ameaça à soberania e respondida com proibições que reafirmavam o monopólio estatal sobre a segurança marítima; e desaprovações de stakeholders que continuavam "não recomendando" ou "desencorajando fortemente" essa prática que aos poucos ganhava força entre os armadores individuais. Por outro lado, os posicionamentos tolerantes incluíram o apoio, por meio da própria contratação dos serviços ou incentivos a essa prática; a aprovação implícita por meio de recomendações e diretrizes, após o reconhecimento de que essa prática já havia ganhado força, apesar de desencorajada ou não recomendada; e a aprovação explícita, por meio de novas legislações autorizando a proteção armada por EMSPs. O Quadro 1 resume os posicionamentos adotados pelos stakeholders nos casos do Estreito de Malaca e do Golfo de Áden, identificados na revisão da literatura. 


\section{Quadro 1 - Posicionamentos dos stakeholders em relação aos serviços de proteção armada} prestados por EMSPs

\begin{tabular}{|c|c|c|c|}
\hline \multicolumn{2}{|c|}{ Stakeholder } & $\begin{array}{l}\text { Sudeste Asiático } \\
\text { (Estreito de Malaca) }\end{array}$ & $\begin{array}{l}\text { Chifre da África } \\
\text { (Golfo de Áden) }\end{array}$ \\
\hline \multicolumn{2}{|c|}{ Armadores individuais } & Apoio (contratação) & Apoio (contratação) \\
\hline \multicolumn{2}{|c|}{$\begin{array}{l}\text { Indústria de seguros } \\
\text { marítimos }\end{array}$} & - & Apoio (incentivo) \\
\hline \multicolumn{2}{|c|}{$\begin{array}{l}\text { Indústria de } \\
\text { transporte marítimo }\end{array}$} & Desaprovação (desincentivo) & Aprovação implícita (orientação) \\
\hline \multicolumn{2}{|c|}{$\begin{array}{c}\text { Organização Marítima } \\
\text { Internacional }\end{array}$} & Desaprovação (desincentivo) & Aprovação implícita (orientação) \\
\hline \multirow{2}{*}{$\begin{array}{l}\text { Estados de } \\
\text { bandeira }\end{array}$} & \begin{tabular}{|c|} 
Registro \\
aberto
\end{tabular} & - & Aprovação implícita (orientação) \\
\hline & $\begin{array}{l}\text { Registro } \\
\text { nacional }\end{array}$ & - & Aprovação explícita (regulação) \\
\hline \multicolumn{2}{|c|}{ Estados costeiros } & Oposição (proibição) & $\begin{array}{c}\text { Aprovação explícita (regulação) } \\
\text { Oposição (proibição) }\end{array}$ \\
\hline \multicolumn{2}{|c|}{ EMSPs } & Defesas individuais & Defesa coletiva \\
\hline
\end{tabular}

Fonte: elaborado pelos autores.

Inicialmente, os serviços de proteção armada no Estreito de Malaca foram prestados discretamente, apoiados apenas pela contratação de armadores individuais, mas sem tentativas de publicizar ou promover as poucas EMSPs atuantes na região (LISS, 2016). Contudo, em 2005, notícias sobre os serviços de proteção armada prestados por EMSPs em águas territoriais de Malásia e Indonésia foram publicadas por um jornal de Singapura, o que suscitou respostas dos dois Estados costeiros. O posicionamento de ambos foi de oposição. Em suas críticas abertas, os serviços de proteção armada eram prestados por empresas sem controle governamental, muitas delas estrangeiras, e constituíam uma violação da soberania de suas águas territoriais - o que levou autoridades malaias a ameaçar detenções (MALAKUNAS, 2005; LISS, 2014; 2017).

Nesse cenário, algumas EMSPs buscaram esclarecer sua condição legal e, individualmente, defenderam publicamente os serviços prestados. Não houve esforços coordenados por parte dos armadores clientes das EMSPs, tampouco por parte das próprias EMSPs, com o objetivo de confrontar a oposição de Malásia e Indonésia. Pelo contrário, essa oposição dos Estados costeiros logo foi endossada 
pela Federation of Asean Shipowners' Associations e pela IMO (MALAKUNAS, 2005; LISS, 2017). De fato, a IMO era contrária à proteção armada de embarcações civis pelo menos desde 1993, quando considerava as consequências legais, a possibilidade de uma escalada da violência e outros riscos do armamento das próprias tripulações (IMO, 1993) - posicionamento estendido para os serviços de proteção armada prestados por EMSPs no Estreito de Malaca. Assim, no decorrer da década, conforme os casos de pirataria e roubo armado diminuíam no Estreito de Malaca, a contratação de EMSPs pelos armadores seguiu a mesma tendência (LISS, 2016).

Diferente das defesas individuais de poucas EMSPs atuantes no Estreito de Malaca, o boom dos serviços de proteção armada diante da pirataria somali foi acompanhado por uma defesa coletiva com a criação de associações das EMSPs, como a International Association of Maritime Security Professionals (IAMSP) e a Security Association for the Maritime Industry (SAMI) (KRASKA, 2013)4. A SAMI, por exemplo, passou a desenvolver normas de acreditação com o objetivo de classificar a reputação das muitas EMSPs que forneciam serviços antipirataria no Golfo de Áden (SAMI, 2014). Um apoio direto à contratação dessas EMSPs no Chifre da África veio na forma de incentivos econômicos da indústria de seguros marítimos. Em maio de 2008, o Golfo de Áden foi incluído na lista de áreas de risco de guerra pelo Joint War Committee (JWC), composto por seguradoras da Lloyd's of London e da International Underwriting Association. ${ }^{5}$ A Somália também era incluída na lista desde 2005, mas a área de risco foi sendo ampliada com a inclusão de países vizinhos e outras áreas marítimas ao longo dos anos (LOBO-GUERRERO, 2012; SINGH; BEDI, 2016). Dada a fragilidade dos Estados costeiros, seguradoras do mercado Lloyd buscaram influenciar as medidas de segurança adotadas pelos próprios armadores, por exemplo, oferecendo descontos para navios com equipes armadas de EMSPs a bordo (BANIELA, 2010; MAHARD, 2014). Em 2008, surgiram as primeiras parcerias entre seguradoras do mercado Lloyd e EMSPs para a prestação desses serviços (MINEAU,

\footnotetext{
${ }^{4}$ Obviamente, além das associações internacionais específicas às EMSPs no domínio marítimo, essa defesa ainda ocorreu por parte de associações nacionais, como a britânica Security in Complex Environments Group (AARSTAD, 2017a).

${ }^{5} \mathrm{O}$ comitê avalia os riscos de guerra que possam afetar os níveis normais de risco por meio dos quais os navios são segurados, produzindo regularmente uma lista de países e áreas que possam representar um nível elevado de risco - denominada Hull War, Strikes, Terrorism and Related Perils List.
} 
2010; MUDRIC, 2011). A atratividade da medida era dada pelo fato de que, em meados de setembro daquele ano, os preços dos seguros já haviam aumentado dez vezes para o envio de cargas através do Golfo de Áden, sendo que os seguros do mercado Lloyd cobriam cerca de $70 \%$ do trânsito na área (COLLINS, 2012; LOBOGUERRERO, 2012).

A relação entre seguradoras e EMSPs ainda envolvia o fato de que a ampliação da área de risco da pirataria somali na lista do JWC se baseava em avaliações realizadas por uma EMSPs, a Aegis Defence Services (AARSTAD, 2017a). Na verdade, o JWC também havia incluído o Estreito de Malaca na lista de áreas de risco de guerra com base em avaliações da Aegis em junho de 2005, mas os resultados foram distintos. Associações da indústria de transporte marítimo criticaram a decisão, considerando que as avaliações da Aegis estabeleciam um nexo entre pirataria e terrorismo (OSNIN, 2006; LISS, 2007; LOBO-GUERRERO, 2012; TOWNSLEY; LECLERC; TATHAM, 2016). Em agosto, Malásia, Indonésia e Singapura solicitaram conjuntamente uma revisão dessa classificação realizada pelo JWC, lamentando que a decisão houvesse sido tomada sem levar em conta seus esforços antipirataria (OSNIN, 2006). De fato, a inclusão do Estreito de Malaca na lista do JWC foi considerada como um estopim para que os três Estados costeiros fortalecessem sua atuação individual e conjunta em operações antipirataria (TOWNSLEY; LECLERC; TATHAM, 2016). O JWC excluiu o estreito da lista em agosto de 2006, levando em conta a diminuição dos ataques e os esforços dos Estados costeiros (LISS, 2007; LOBO-GUERRERO, 2012).

De modo semelhante ao que havia ocorrido no Estreito de Malaca, a crescente contratação das EMSPs pelos armadores no Chifre da África não foi uma ideia bem recebida na indústria de transporte marítimo (KRASKA; WILSON, 2009). Desde 2009, as Best Management Practices (BMPs) da indústria passaram a ser elaboradas diante da pirataria somali. Até sua terceira versão, publicada em junho de 2010, as BMP3 não recomendavam a contratação de equipes armadas para a proteção dos navios, atribuindo essa responsabilidade às forças navais e encorajando os armadores a adotar outras medidas defensivas não letais. ${ }^{6}$ Individualmente, outros stakeholders da

\footnotetext{
${ }^{6}$ As BMPs também foram apoiadas pelo JWC, apesar dos incentivos econômicos à contratação das EMSPs por parte de seguradoras do mercado Lloyd.
} 
indústria de transporte marítimo também manifestaram sua desaprovação à prática que ganhava força entre os armadores individuais. Em 2008, um dos diretores da ICS explicou a desaprovação à proteção armada por EMSPs em virtude da obrigação dos Estados em prover passagem segura para o comércio mundial, tornando insatisfatória a opção de devolver tal responsabilidade para os próprios armadores. No mesmo ano, o chefe de segurança marítima do BIMCO declarou essa desaprovação dizendo que a prática era tentadora, mas gerava um grave risco de escalada da violência (SPEARIN, 2010a; 2010b).

Contudo, a crescente contratação de EMSPs pelos armadores individuais no Chifre da África gradualmente provocou mudanças no posicionamento desses e outros stakeholders, principalmente a partir de 2011. Se até então havia desencorajado que seus membros recorressem à proteção armada, o presidente da ICS sustentou que os armadores deveriam contar com todas as opções contra a pirataria somali, sendo que a decisão pela contratação de EMSPs deveria ser tomada após aprovação do Estado de bandeira e das seguradoras - mas ainda assim uma segunda opção em comparação aos VPDs e não recomendada em circunstâncias normais (DUTTON, 2013). Um dos gerentes da associação ressaltou que essa decisão era uma resposta ao fato de que os serviços prestados por EMSPs já estavam sendo utilizados pelos armadores (AARSTAD, 2017a). O BIMCO também reconheceu que a proteção armada por EMSPs era algo que infelizmente havia se tornado comum entre os armadores, por isso somou esforços com outras entidades no desenvolvimento de orientações e diretrizes, incluindo um contrato padrão para o emprego de equipes de EMSPs a bordo dos navios, intitulado GUARDCON. Um dos objetivos do contrato era auxiliar os armadores e seus Clubes P\&I, garantindo que a proteção armada não prejudicasse a cobertura dos seguros (KRASKA, 2013; BIMCO, 2017). Ao final do ano, o IGP\&I também reconheceu que uma mudança de posicionamento já havia ocorrido no interior da indústria (MUDRIC, 2011). Esses novos posicionamentos das associações da indústria foram cristalizados em uma nova versão das BMPs, publicada em agosto de 2011. Segundo Aarstad (2017a), a BMP4 minimizou a antiga oposição e se aproximou de uma autorização implícita, por meio de diretrizes e recomendações que reconheciam a contratação de EMSPs como uma decisão dos armadores, embora a prática não fosse encorajada em detrimento 
de outras medidas defensivas. De fato, no caso da decisão pela proteção armada, a BMP4 recomendava os VPDs, em vez das EMSPs (FARNELLI, 2015; TUERK, 2015).

Posicionamento semelhante foi estabelecido pela IMO, no âmbito de seu Comitê de Segurança Marítima (MSC). Ainda que a agência desaprovasse a proteção armada realizada por tripulantes pelo menos desde 1993, quando desencorajava fortemente a prática, as primeiras mudanças nesse posicionamento vieram em 2008, quando o MSC passou a emitir recomendações e diretrizes provisórias diante da crescente contratação de EMSPs no Chifre da África (LISS, 2017). Em maio de 2011, o MSC firmou explicitamente seu posicionamento que autoriza implicitamente a prática. A agência declara que não apoia ou condena a proteção armada realizada por EMSPs, mas aceita que a contratação desses serviços é uma decisão dos armadores, sujeita às leis do Estado de bandeira do navio (IMO, 2017). De fato, o MSC reconheceu que a prática já era comum entre os armadores e, em determinadas circunstâncias, também entre Estados de bandeira, justificando a necessidade das recomendações e diretrizes - que, ao longo do tempo, foram direcionadas aos armadores e capitães; Estados de bandeira; Estados costeiros do Chifre da África; bem como às próprias EMSPs (MUDRIC, 2011; PRIDDY; CASEY-MASLEN, 2012; CHAPSOS; HOLTOM, 2015). Contudo, a IMO também enfatiza que a proteção armada por EMSPs não deve ser considerada uma alternativa às demais medidas defensivas das BMPs (MUDRIC, 2011).

Um dos principais objetivos das recomendações e diretrizes da IMO era garantir a conformidade da proteção armada com as legislações nacionais. Como Liss (2016) chama atenção, a maioria dos Estados não possuía regulações específicas sobre a proteção armada dos navios registrados sob sua bandeira, uma vez que essa não era uma prática comum na indústria do transporte marítimo. A atuação das EMSPs no Estreito de Malaca não mudou essa situação, mas após o aumento da pirataria somali, segundo a autora, é possível identificar duas diferentes respostas dadas pelos Estados de bandeira, dependendo de seu registro aberto ou nacional. ${ }^{7}$ Grande parte dos países de registro aberto, que são as maiores bandeiras de registro do mundo,

\footnotetext{
${ }^{7}$ Nos registros abertos, os navios não precisam ser propriedade de cidadãos ou ter sido construídos no país; os impostos sobre os navios são bastante baixos; e as regulações são pouco estritas. Por esses e outros motivos, os registros abertos também são denominados bandeiras de conveniência. As principais bandeiras de registro da frota mercante mundial são bandeiras de conveniência (DE NEVERS, 2015a).
} 
autorizaram implicitamente a prática. Ao nem apoiar e nem proibir, esses países deixaram aberta a possibilidade para que armadores ou capitães decidam pela contratação desses serviços e assumam as responsabilidades decorrentes. Entre os principais países de registro aberto, Panamá, Libéria, Ilhas Marshall, Malta, Bahamas, Bermudas e Antígua e Barbuda, por exemplo, adotaram esse posicionamento e se limitaram a elaborar diretrizes oficiais sobre a proteção armada a bordo dos navios sob sua bandeira, e apenas Chipre estabeleceu uma legislação para autorizar explicitamente a prática (VAN HESPEN, 2014). Essas autorizações implícitas se aproximam dos posicionamentos da indústria de transporte marítimo e da IMO, com muitas diretrizes oficiais dos países de registro aberto limitando-se a recomendar que os navios sob sua bandeira adotem as BMPs da indústria e as recomendações e diretrizes da IMO. De fato, países de registro aberto, como a Libéria, em 2011, também atuaram propondo diretrizes sobre o uso de EMSPs diretamente à IMO, enquanto Ilhas Marshall e Bahamas recomendaram a criação de uma associação das EMSPs para que os Estados de bandeira direcionassem seus armadores na contratação desses serviços (KRASKA, 2013) - a SAMI seria criada logo depois.

Grande parte dos países com registro nacional, por sua vez, autorizaram explicitamente essa prática ao estabelecer novas legislações sobre a proteção armada por EMSPs (LISS 2016). A literatura especializada apresenta muitas análises desses novos marcos regulatórios, incluindo os casos da Itália (BEVILACQUA, 2013; CUSUMANO; RUZZA, 2015), Espanha (BÜRGIN, 2012; PATRÓN, 2012; 2014) e Noruega (AARSTAD, 2017b), além de análises comparativas sobre Espanha e Alemanha (BÜRGIN E SCHNEIDER, 2015), Noruega e Estados Unidos (MAHARD, 2014); Noruega, Dinamarca e Suécia (BERNDTSSON E ØSTENSEN, 2015); Estados Unidos e Reino Unido (DE NEVERS, 2015b); e Estados Unidos, Reino Unido, Dinamarca, Noruega e Singapura (DUTTON, 2013). Cada vez mais Estados de bandeira passaram a autorizar explicitamente a proteção armada por EMSPs, incluindo países que antes se opunham à prática, tais como Grécia e Japão (LISS, 2016; 2017). Obviamente, as novas regulações variam substancialmente. Entre os países que autorizaram explicitamente a prática, Estados Unidos e Reino Unido adotaram uma postura próxima ao apoio (AFFI et al., 2016), mas também há casos de autorização apenas diante da indisponibilidade de VPDs, como na Itália (CUSUMANO; RUZZA, 2015), e mesmo de oposição à proteção armada por EMSPs, 
autorizando apenas VPDs, como na Holanda - uma exceção entre os Estados de bandeira europeus (VAN HESPEN, 2014). ${ }^{8}$

No caso dos Estados costeiros próximos ao Chifre da África, não existem regulações padronizadas sobre a questão. De acordo com o levantamento de Chapsos e Holtom (2015), alguns Estados se opõem à entrada de armas em suas águas territoriais, seja pela legislação nacional, como nos Emirados Árabes, seja por embargos de armas da ONU, como na Eritreia e na própria Somália. Outros autorizam a entrada de armas, desde que anunciadas antecipadamente. Por exemplo, na Arábia Saudita, as armas devem ser armazenadas e trancadas a bordo do navio durante a passagem através de suas águas, enquanto em países como Quênia, Ilhas Maurício e Omã, as armas devem ser desembarcadas e armazenadas sob a supervisão das forças estatais sob a cobrança de uma taxa. Alguns países chegaram a estabelecer arranjos para o aluguel de armas estatais, como Djibuti e Sri Lanka (PRIDDY; CASEYMASLEN, 2012; PETRIG, 2013). Contudo, a literatura identifica diversas estratégias utilizadas pelas EMSPs para contornar as regulações desses Estados costeiros, principalmente a contratação de arsenais flutuantes - embarcações localizadas em alto-mar, geralmente propriedade de EMSPs, que prestam serviços complementares como o armazenamento de armas, munições e equipamentos. Assim, as equipes e suas armas podem embarcar nos navios mercantes após entrar em águas internacionais e desembarcar antes de entrar em águas territoriais (PETRIG, 2013). Em 2014, quase 40 arsenais flutuantes atuavam nas águas próximas ao Chifre da África, em sua maioria ligados a Estados de bandeira com registro aberto. Até então, o interesse desses registros em regular ou monitorar a operação dos arsenais flutuantes havia sido limitado (CHAPSOS; HOLTOM, 2015).

Em suma, diferentes condições parecem ter definido os posicionamentos dos stakeholders perante as EMSPs nos dois casos. No Estreito de Malaca, os Estados costeiros reivindicaram a responsabilidade pela segurança marítima e se opuseram diretamente aos serviços de proteção armada prestados por EMSPs, ainda pouco consolidadas enquanto indústria. Como resultado, stakeholders como a indústria de transporte marítimo e a IMO mantiveram o consenso estabelecido até então,

\footnotetext{
${ }^{8}$ A ICS publica uma lista com as diretrizes e legislações dos Estados de bandeira. Disponível em: $<$ https://www.ics-shipping.org/docs/default-source/Piracy-Docs/comparison-of-flag-state-laws-onarmed-guards-and-arms-on-board-2017.pdf?sfvrsn=0 > Acessado em 21/01/2020.
} 
desaprovando a proteção armada por EMSPs. No Golfo de Áden, com a particularidade dos altos custos humanos e econômicos da pirataria baseada em sequestros, somados à fragilidade do Estado somali e à fragmentação do território entre grupos envolvidos com a pirataria, as próprias respostas estatais foram singulares, como as operações multilaterais em águas de jurisdição exclusiva do Estado costeiro e a disponibilização de equipes estatais a bordo. Contudo, com a ampliação da área de risco dos ataques, oposições e desaprovações gradualmente deram lugar a aprovações implícitas e explícitas aos serviços de proteção armada por EMSPs, fortalecidas enquanto indústria por meio de associações e serviços complementares.

Contudo, essa passagem de posicionamentos reprobatórios a tolerantes ainda carrega limitações ao papel atribuído às EMSPs na segurança marítima, considerada como uma segunda opção em comparação às equipes estatais e, na melhor das hipóteses, um mal necessário perante as circunstâncias específicas da pirataria somali. Em grande medida, os novos posicionamentos adotados pela maioria dos stakeholders aprovaram implicitamente um processo de privatização bottom-up que já estava em curso pelos próprios armadores, mas não buscaram institucionalizar a medida. Um resultado desse posicionamento foi a resistência de stakeholders como a IMO e os Estados de bandeira às tentativas de autorregulação das EMSPs pela SAMI, por exemplo (AARSTAD, 2017a; MARITIME CYPRUS, 2016). Assim, a segurança marítima continua ancorada no Estado e a proteção armada dos navios mercantes continua sendo fonte de preocupação por suas consequências legais, pelo risco de uma escalada da violência, pelos desafios à autoridade dos capitães e outros dilemas (FLORQUIN, 2012). Se muitos stakeholders respondem autorizando implicitamente a opção feita pelos armadores, isso quer dizer que o equilíbrio entre as antigas preocupações relacionadas à proteção armada e as condições excepcionais da pirataria somali pendem para o lado que considera a necessidade de medidas preventivas igualmente excepcionais.

\section{CONCLUSÃO}

A proteção armada por equipes a bordo de navios mercantes tem sido um dos serviços antipirataria mais proeminentes e controversos prestados por EMSPs. Refletindo uma divisão de tarefas que resultou no desarmamento das embarcações 
civis e na responsabilidade estatal pela segurança nos mares há pelo menos um século e meio, muitos stakeholders do transporte marítimo sustentavam posicionamentos contrários a essa prática. Enquanto esses posicionamentos reprobatórios foram mantidos no caso do Estreito de Malaca, a pirataria somali no Golfo de Áden representou um ponto de inflexão, com posicionamentos mais tolerantes sendo gradualmente identificados pela literatura de modo fragmentado e genérico. Este artigo revisou a literatura especializada com o objetivo de entender as condições e a direção desses novos posicionamentos sobre a proteção armada de navios mercantes por EMSPs.

A análise revela que as indústrias do transporte e dos seguros marítimos, a IMO e os Estados de bandeira e costeiros estão entre os stakeholders que assumiram posicionamentos mais tolerantes diante da crescente contratação de EMSPs por armadores no Golfo de Áden. Em grande medida, ao recorrer às EMSPs para proteger suas frotas da pirataria somali, os armadores promoveram um processo bottom-up de privatização da segurança marítima. A legitimação desse mercado pelos demais stakeholders ocorreu num contexto em que respostas estatais bastante singulares foram dadas à pirataria somali em razão da fragilidade do Estado costeiro e dos altos custos humanos e econômicos dos sequestros, mas que ainda deixavam lacunas e demandas de segurança por parte dos próprios navios mercantes. Essas condições fizeram das EMSPs uma opção cada vez mais usada pelos armadores e posteriormente reconhecida explícita ou implicitamente pela maioria dos stakeholders. Já no Estreito de Malaca, o crescimento da pirataria foi combatido diretamente pelos Estados costeiros, mais sólidos e dispostos a reivindicar a responsabilidade pela segurança marítima como forma de defender sua soberania, inclusive se opondo fortemente à proteção armada realizada por EMSPs. A indústria de transporte marítimo e a IMO logo endossaram esses posicionamentos reprobatórios e defenderam a responsabilidade estatal pela segurança marítima.

Ainda que esses fatores sejam semelhantes às dinâmicas de oferta e demanda que legitimaram as EMSPs em terra, os serviços de proteção armada nos mares continuam sendo considerados como uma segunda opção em relação às respostas estatais e envoltos em preocupações específicas ao domínio marítimo. Assim, os casos analisados permitem sugerir a hipótese de que a oferta de serviços de proteção armada e a constituição desse mercado de segurança marítima se legitima quando 
estão presentes duas principais condições de demanda. Por um lado, riscos exacerbados e consequências graves, como um aumento vertiginoso nos ataques piratas envolvendo sequestros em corredores estratégicos do transporte internacional, com altos custos humanos e econômicos. Por outro, a insuficiência das respostas estatais, seja por sua ocorrência em regiões sob domínio ou influência de Estados institucionalmente frágeis e com pouca capacidade ou disposição para lidar com o problema, seja pelos resultados limitados de operações multilaterais que buscam compensar essa mesma incapacidade ou indisposição estatal. Sob tais condições, as preocupações relacionadas à proteção armada dão lugar à necessidade de medidas defensivas alternativas, ainda que excepcionais. Testar a validade dessa hipótese a partir da análise de outros casos é o desafio que fica para estudos futuros.

\section{REFERÊNCIAS BIBLIOGRÁFICAS}

AARSTAD, Åsne. Maritime security and transformations in global governance. Crime, Law and Social Change, v. 67, n. 3, p. 313-331, 2017 a.

. Who governs Norwegian maritime security? Public facilitation of private security in a fragmented security environment. Cooperation and Conflict, v. 52, n. 2, p. 261-279, 2017b.

AFFI, Ladan; ELMI, Afyare; KNIGHT, W. Andy; MOHAMED, Said. Countering piracy through private security in the Horn of Africa: prospects and pitfalls. Third World Quarterly, v. 37, n. 5, p. 1-17, 2016

AVANT, Deborah. The market for force: the consequences of privatizing security. Cambridge: Cambridge University Press, 2005.

BALTIC AND INTERNATIONAL MARITIME COUNCIL (BIMCO). GUARDCON: standard contract for the employment of security guards on vessels. 2017. Disponível em: $\quad<$ https://www.bimco.org/-/media/bimco/news-and-trends/news/pressreleases/2017/guardcon-explanatory-notes-v14--2017-update.ashx> Acessado em 28 de dezembro de 2017.

BANCO MUNDIAL. Pirate trails: tracking the illicit financial flows from piracy off the Horn of Africa. Washington, DC: World Bank, 2013. Disponível em: < http://documents.worldbank.org/curated/en/408451468010486316/pdf/Pirate-trailstracking-the-illicit-financial-flows-from-pirate-activities-off-the-Horn-of-Africa.pdf> Acessado em 26 de janeiro de 2020.

BANIELA, Santiago. Piracy at sea: Somalia an area of great concern. The Journal of Navigation, v. 63, n. 2, p. 191-206, 2010. 
BECKMAN, Robert; PAGE, Monique. Piracy and armed robbery against ships. In: GILL, Martin (ed.). The handbook of security. 2. ed. Basingstoke: Palgrave Mcmillan, 2014, p. 234-255.

BERNDTSSON, Joakim; ØSTENSEN, Ase. The Scandinavian approach to private maritime security - a regulatory façade? Ocean Development \& International Law, vol. 46, n. 2, p. 138-152, 2015.

BERUBE, Claude. Blackwaters for the blue waters: the promise of private naval companies. Orbis, v. 51, n. 4, p. 601-615, 2007.

BEVILACQUA, Giorgia. Counter piracy armed services, the Italian system and the search for clarity on the use of force at sea. The Italian Yearbook of International Law Online, v. 22, n. 1, p. 39-57, 2013.

BROWN, James. Pirates and privateers: managing the Indian Ocean's private security boom. Sydney: Lowy Institute for International Policy Analysis, 2012.

BURGESS, Douglas. Hostis humani generi: piracy, terrorism and a new international law. University of Miami International and Comparative Law Review, v. 13, n. 2, p. 293341, 2006.

BÜRGIN, Annina. Spanish maritime security governance in the Indian Ocean region. Journal of the Indian Ocean Region, v. 8, n. 2, p. 127-141, 2012.

; SCHNEIDER, Patricia. Regulation of private maritime security companies in Germany and Spain: a comparative study. Ocean Development \& International Law, v. 46, n. 2, p.123-137, 2015.

CHALK, Peter. The maritime dimension of international security: terrorismo, piracy, and challenges for the United States. Santa Monica, CA: RAND Corporation, 2008.

CHAPSOS, loannis; HOLTOM, Paul. Stockpiles at sea: floating armouries in the Indian Ocean. In: SMALL ARMS SURVEY. Small arms survey 2015: weapons and the world. Cambridge: Cambridge University Press, 2015, p. 217-241.

COLLINS, Victoria. Dangerous seas: moral panic and the Somali pirate. Australian \& New Zealand Journal of Criminology, v. 45, n. 1, p. 106-132, 2012.

CUSUMANO, Eugenio; RUZZA, Stefano. Contractors as a second best option: the Italian hybrid approach to maritime security. Ocean Development \& International Law, v. 46, n. 2, p. 111-122, 2015.

DE NEVERS, Renée. Sovereignty at sea: states and security in the maritime domain. Security Studies, v. 24, n. 4, p. 597-630, 2015a. 
. State interests and the problem of piracy: comparing U.S. and UK approaches to maritime PMSCs. Ocean Development \& International Law, v. 46, n. 2, p. 597-630, $2015 b$.

DUTTON, Yvonne. Gunslingers on the high seas: a call for regulation. Duke Journal of Comparative \& International Law, v. 24, n. 1, p. 107-160, 2013.

FARNELLI, Gian. Vessel protection detachments and maritime security: an evaluation of four years of Italian practice. Maritime Safety and Security Law Journal, v. 1, 2015.

FLORQUIN, Nicolas. Escalation at sea: Somali piracy and private security companies. In: SMALL ARMS SURVEY. Small arms survey 2012: moving targets. Cambridge: Cambridge University Press, 2012, p. 191-217.

FRÉCON, Eric. The resurgence of sea piracy in Southeast Asia. Bangkok: Institut de recherche sur l'Asie du Sud-Est contemporaine, Irasec Occasional Paper n. 5, 2008.

GHOSH, Probal Kumar. Strategies for countering Somalian piracy: responding to the evolving threat. India Quarterly, v. 70, n. 1, p. 15-31, 2014.

HANSEN, Stig Jarle. Private security \& local politics in Somalia. Review of African Political Economy, v. 35, n. 118, p. 585-598, 2008.

HARLOW, James W. Soldiers at sea: the legal and policy implications of using military security teams to combat piracy. Southern California Interdisciplinary Law Journal, v. 21, n. 3, p. 561-602, 2012.

INTERNATIONAL MARITIME BUREAU (IMB). Piracy and armed robbery against ships: annual report 1 january - 31 december 2004. London: ICC-IMB, 2005. Disponível em: <https://www.peacepalacelibrary.nl/ebooks/files/ICC_InternationalMaritimeBoard_An nual_Piracy_Report2004.pdf> Acessado em 26 de janeiro de 2020.

. Piracy and armed robbery against ships: annual report 1 january - 31 december 2008. London: ICC-IMB, 2009. Disponível em: <https://www.rk-marinekiel.de/files/piraterie/imb/IMB_Piracy_Report_2008.pdf> Acessado em 26 de janeiro de 2020.

Piracy and armed robbery against ships: anual report 1 january - 31 december 2009. London: ICC International Maritime Bureau, 2010. Disponível em: <https://www.rk-marine-kiel.de/files/piraterie/imb/IMB_Piracy_Report_2009.pdf> Acessado em 26 de janeiro de 2020.

. Piracy and armed robbery against ships: annual report 1 january - 31 december 2012. London: ICC-IMB, 2013. Disponível em: <https://www.kvnr.nl/stream/2012-annual-imb-piracy-report> Acessado em 26 de janeiro de 2020. 
INTERNATIONAL MARITIME ORGANIZATION (IMO). Guidance to shipowners and ship operators, shipmasters and crews on preventing and suppressing acts of piracy and armed robbery against ships. MSC/Circ.623, 1993. Disponível em: <http://www.mcw.gov.cy/mcw/dms/dms.nsf/0/96C301662E82B1C0C225751D002EE 6B9/\$file/1-5\%20(\%2023-09-1993).pdf> Acessado em 18 de dezembro de 2017.

. Interim guidance to shipowners, ship operators, and shipmasters on the use of privately contracted armed security personnel on board ships in the high risk area. MSC.1/Circ.1405, 2011. Disponível

em: <https://www.ukpandi.com/fileadmin/uploads/ukpi/Latest_Publications/Circulars/MSC.1-Circ.1405.pdf> Acessado em 16 de janeiro de 2018.

Private armed security. 2017. Disponível em: <http://www.imo.org/en/OurWork/Security/PiracyArmedRobbery/Pages/PrivateArmed-Security.aspx> Acessado em 02 de julho de 2017.

KISIANGANI, Emmanuel. Somali pirates: villains or victims? South African Journal of International Affairs, v. 17, n. 3, p. 361-374, 2010.

KRASKA, James. International and comparative regulation of Private Maritime Security Companies employed in counter-piracy. In: GUILFOYLE, Douglas (ed.). Modern piracy: legal challenges and responses. Cheltenham/Northampton: Edward Elgar Publishing Limited, 2013, p. 219-249.

; WILSON, Brian. The pirates of the Gulf of Aden: the coalition is the strategy. Stanford Journal of International Law, v.45, n. 2, p. 241-284, 2009.

LISS, Carolin. Southeast Asia's maritime security dilemma: state or market? The AsiaPacific Journal, v. 5, n. 6, p. 1-25, 2007.

. New actors and the state: addressing maritime security threats in Southeast Asia. Contemporary Southeast Asia, v. 35, n. 2, p. 141-162, $2013 a$.

. Private military and security companies in maritime security governance. In: JAKOBI, Anja; WOLF, Klaus (ed.). The transnational governance of violence and crime: non-state actors in security. London/New York: Palgrave Macmillan, 2013b, p.193-213.

The privatisation of maritime security in Southeast Asia: the impact on regional security cooperation. Australian Journal of International Affairs, v. 68, n. 2, p. 194-209, 2014.

PMSCS in maritime security and anti-piracy control. In: ABRAHAMSEN, Rita; LEANDER, Anna (ed.). Routledge handbook of private security studies. Abindgon/New York: Routledge, 2016, p.61-69.

. Challenging sovereignty and state control of violence at sea? The operations of private anti-piracy security providers. In: GERTHEISS, Svenja et al (ed.). Resistance 
and change in world politics: international dissidence. Cham: Palgrave Macmillan, 2017, p. 79-108.

LOBO-GUERRERO, Luis. Los seguros marítimos y la movilidad como biopolítica de seguridad. Política y Sociedad, v. 49, n. 3, p. 533-547, 2012.

LORCA, Beatriz. Harmonisation of national criminal laws on maritime piracy: a regulatory proposal for the crime of piracy and its penalties. European Journal of Criminal Policy and Research, v. 23, n. 2, p. 115-132, 2017.

MAHARD, Sean. Blackwater's new battlefield: toward a regulatory regime in the United States for privately armed contractors operating at sea. Vanderbilt Journal of Transnational Law, v. 47, n. 1, p. 331-369, 2014.

MALAKUNAS, Karl. Private armed escorts in high demand on sea. CorpWatch, 11. maio. 2005. Disponível em: <https://corpwatch.org/article/world-private-armedescorts-high-demand-sea> Acessado em 27 de dezembro de 2017.

MARITIME CYPRUS. The Security Association for the Maritime Industry (SAMI) announces voluntary liquidation. 2016. Disponível em: <https://maritimecyprus.com/2016/04/19/the-security-association-for-the-maritimeindustry-sami-announces-voluntary-liquidation/> Acessado em 21/01/2020.

MINEAU, Michael. Pirates, Blackwater and maritime security: the rise of private navies in response to modern piracy. The Journal of International Business \& Law, v. 9, n.1, p. $63-78,2010$.

MUDRIC, Miso. Armed guards on vessels: insurance and liability. Comparative Maritime Law, v. 50, n. 165, p. 217-268, 2011.

OCEANS BEYOND PIRACY (OBP). The economic cost of somali piracy 2011. One Earth Future Foundation, 2012. Disponivel em: $<$ http://oceansbeyondpiracy.org/sites/default/files/economic_cost_of_piracy_2011.pdf > Acessado em 27 de janeiro de 2018.

. The economic cost of somali piracy 2012. One Earth Future Foundation,
Disponivel http://oceansbeyondpiracy.org/sites/default/files/attachments/View\%20Full\%20Repor t_3.pdf> Acessado em 27 de janeiro de 2018.

Disponível

The state of maritime piracy 2013. One Earth Future Foundation, 2014. <http://oceansbeyondpiracy.org/sites/default/files/attachments/SoP2013-Digital_0_01.pdf $>$ Acessado em 27 de janeiro de 2018.

. The state of maritime piracy 2014: assessing the economic and human cost. One Earth Future Foundation, 2015. Disponível em: <http://oceansbeyondpiracy.org/sites/default/files/attachments/StateofMaritimePiracy 2014.pdf> Acessado em 27 de janeiro de 2018. 
. The state of maritime piracy 2015: assessing the economic and human cost. One Earth Future Foundation, 2016. Disponível em: <http://oceansbeyondpiracy.org/sites/default/files/State_of_Maritime_Piracy_2015.pd f> Acessado em 27 de janeiro de 2018.

. The state of maritime piracy 2016: assessing the economic and human cost. One Earth Future Foundation, 2017. Disponivel em <http://oceansbeyondpiracy.org/sites/default/files/one_earth_future_state_of_piracy_r eport_2016.pdf> Acessado em 27 de janeiro de 2018.

. The state of maritime piracy 2017: assessing the economic and human cost. One Earth Future Foundation, 2018. Disponível em: $<$ http://oceansbeyondpiracy.org/sites/default/files/one_earth_future_state_of_piracy_r eport_2017.pdf> Acessado em 16 de janeiro de 2019.

ORGANIZAÇÃO DAS NAÇÕES UNIDAS (ONU). Convenção das Nações Unidas sobre o Direito do Mar, adotada em 10 de dezembro de 1982. Disponível em: < https://www.un.org/depts/los/convention_agreements/texts/unclos/unclos_e.pdf> Acessado em 02 de julho de 2017.

ONUOHA, Freedom. Sea piracy and maritime security in the Horn of Africa: the Somali coast and Gulf of Aden in perspective. African Security Review, v. 18, n. 3, p. 31-44, 2009.

OSNIN, Noor Apandi. Private Maritime Security Company (PMSC) in the Strait of Malacca - Options for Malaysia. WMU Journal of Maritime Affairs, v. 5, n. 2, p. 195206, 2006.

PAOLIELLO, Tomaz. Anatomia de uma empresa militar e de segurança privada: a empresa DynCorp em perspectiva global. Tese de Doutorado em Relações Internacionais. UNESP/UNICAMP/PUC-SP, 2016.

PATRÓN, José Manuel Sánchez. Piratería marítima, fuerza armada y seguridad privada. Revista Electrónica de Estudios Internacionales, v. 23, p. 1-20, 2012.

La legitima defensa ante la piratería marítima. Revista Electrónica de Estudios Internacionales, v. 28, p. 1-39, 2014.

PETRIG, Anna. The use of force and firearms by Private Maritime Security Companies against suspected pirates. International and Comparative Law Quarterly, v. 62, n. 3, p. 667-701, 2013.

PRIDDY, Alice; CASEY-MASLEN, Stuart. Counter-piracy operations by private maritime security contractors: key legal issues and challenges. Journal of International Criminal Justice, v. 10, n. 4, p. 839-856, 2012.

RAYMOND, Catherine. Piracy and armed robbery in the Malacca Strait. Naval War College Review, v. 62, n. 3, p. 31-42, 2009. 
SECURITY ASSOCIATION FOR THE MARITIME INDUSTRY (SAMI). The evolution of the Security Association for the Maritime Industry (SAMI) and piracy in the Indian Ocean. 2014. Disponível em: <http://www.lessonsfrompiracy.net/files/2014/06/DRAFT-The-Evolution-of-theSecurity-Association-for-the-Maritime-Industry-8-May-14.pdf> Acessado em 27 de janeiro de 2018.

SEKULICH, Daniel. Terror nos mares: os piratas do século 21. São Paulo: Editora Landscape, 2009.

SINGER, Peter. Corporate warriors: the rise of the privatized military industry. Ithaca/London: Cornell University Press, 2008.

SINGH, Currun; BEDI, Arjun. War on piracy: the conflation of Somali piracy with terrorism in discourse, tactic, and law. Security Dialogue, v. 47, n. 5, p. 440-458, 2016.

SPEARIN, Christopher. A private security solution to Somali piracy? The U.S. call for private security engagement and the implications for Canada. Naval War College Review, v. 63, n. 4, p. 56-71, 2010a.

- Against the current? Somali pirates, private security, and American responsibilization. Contemporary Security Policy, v. 31, n. 3, p. 553-568, $2010 \mathrm{~b}$.

TOWNSLEY, M.; LECLERC, B.; TATHAM, P. How super controllers prevent crimes: learning from modern maritime piracy. British Journal of Criminology, v. 56, n. 3, p. 537-557, 2016.

TUERK, Helmut. Combating piracy: new approaches to an ancient issue. In: CASTILLO, Lilian (ed.). Law of the sea, from Grotius to the International Tribunal for the Law of the Sea. Leiden: Brill/Nijhoff, 2015, p. 469- 492.

VAN GINKEL, Bibi; LANDMAN, Lennart. In search of a sustainable and coherent strategy: assessing the kaleidoscope of counter-piracy activities in Somalia. Journal of International Criminal Justice, v. 10, n. 4, p. 727-748, 2012.

; VAN DER PUTTEN, Frans-Paul; MOLENAAR, Willem. State or private protection against maritime piracy? A Dutch perspective. Netherlands Institute of International Relations, 2013.

VAN HESPEN, Ilja. Protecting merchant ships from maritime piracy by Privately Contracted Armed Security Personnel: a comparative analysis of flag state legislation and port and coastal state requirements. Journal of Maritime Law \& Commerce, v. 45, n. 3, p. 361- 400, 2014.

Recebido em: 27/01/2020

Aprovado em: 06/09/2020 